\title{
Research of the soybean oil extraction using polar solvents
}

\author{
$\underline{\text { Anna Hlukhaniuk }}^{1}$, Oleksandr Ivashchuk ${ }^{1}$, Yevgen Semenyshyn ${ }^{1}$, \\ Roman Chyzhovych ${ }^{1}$, Tetiana Kuzminchuk ${ }^{1}$, Semen Khomyak ${ }^{2}$
}

1. Department of Chemical Engineering, Lviv Polytechnic National University, UKRAINE, Lviv, 12 Bandery str., E-mail: anna.hlukhaniuk.mnxt.2019@lpnu.ua

2. Department of Technology of Biologically Active Substances, Pharmacy and Biotechnology, Lviv Polytechnic National University, UKRAINE, Lviv, 12 Bandery str.

\begin{abstract}
The article considers the peculiarities of the process of vegetable oil extraction using polar solvents. It is shown that the efficiency of using polar solvents for the extraction of soybean oil depends on the nature and physicochemical properties of the solvent.
\end{abstract}

Keywords - extraction, polar solvents, vegetable oil, soybean oil, extraction efficiency

\section{Introduction}

The main traditional oilseeds are soybeans, rapeseed, and sunflower. The industrial removal of oil from vegetable raw materials is realized by pressing and extraction [1]. The main disadvantage of existing technologies is the high content of residual oil in the semi-fat meal (about 20\%). Therefore, there is a need to find more effective methods of extracting oil from raw materials [2].

There are various factors influencing the quantitative parameters of the efficiency of the extraction process, but along with investigation of increasing the efficiency it is necessary to investigate in detail the qualitative parameters of the obtained target component, both to determine the influence of the nature of the extractant on the chemical state of oils and for further planning the purification stages according to technological requirements [3].

\section{Research basics}

The extraction method is widely used in world industry due to the high efficiency of extraction of oils not only from raw materials with a high content of the target component but also those where the concentration of the latter does not exceed 5\% [2, 4].

The technical design and operating conditions of the extraction process are determined by the properties of the selected solvent. Comparative experimental studies have shown that polar solvents are more effective in dissolving vegetable oils [5].

Due to the fact that the extraction of oil from vegetable raw materials includes both intramolecular transfer of components to the phase contact surface and external diffusion from the phase contact surface to the bulk of the solvent, the effect of grinding on the extraction efficiency was investigated. The obtained data indicate a direct effect of grinding on the intensification of the extraction of the target component [5].

It is important to control the quality and composition of the extracted oil too. The main indicators that determine the properties and quality of oil are the number of saponification, iodine, acid and ester numbers. Also for quality control of oil raw materials are used methods of refractometry and various types of spectroscopic analysis.

\section{Experimental}

Soybean raw material was grinded and distributed by sieve fractionation with different particle sizes of $0.2 \mathrm{~mm}, 0.5 \mathrm{~mm}, 1.0 \mathrm{~mm}$ and an average mixture of crushed fractions, and dried to a moisture content of 2-5\%. Polar solvents were used: dichloromethane, ethanol, isopropanol, 
n-propanol. The extraction of soybean vegetable oil using polar solvents was carried out in the Soxhlet apparatus for 8 hours at a solvent's boiling temperature. Sampling was performed every 2 hours.

Among the important controlled parameters according to the current standards, during the experimental studies were determined chemical constants (acid number, iodine number, ester number, saponification number, etc.) according to the methods [6], as well as optical and spectral properties by refractometry and UV-Vis -spectroscopy and IR spectroscopy, the latter in particular to confirm the presence of major functional groups and to detect abnormalities.

Determination of the refractive index of the oil was performed according to the method [7]. Ultraviolet spectroscopy (UV-Vis) data, obtained on a spectrophotometer, model ULAB 108UV Spectrophotometer, operating in the range of $190-1100 \mathrm{~nm}$.

IR spectroscopic examination was performed on a spectrophotometer SPECORD M80 (Carl Zeiss Jena) in thin films, range $4000-400 \mathrm{~cm}^{-1}$.

\section{Results and discussion}

The results of quantitative analysis of extraction are given in the form of graphical scales of oil concentration in selected signs from time $\mathrm{C}=\mathrm{f}(\mathrm{t})($ Fig. 1, 2) for each fraction.

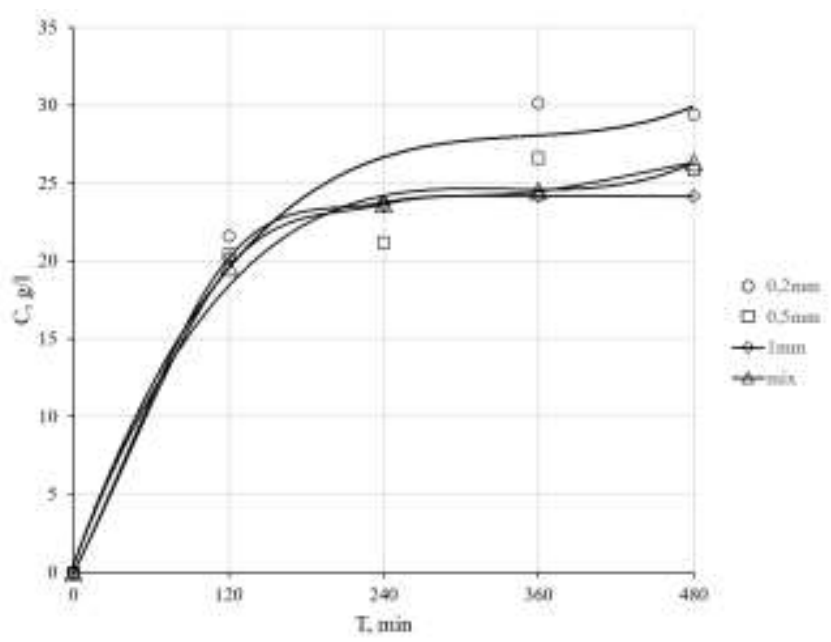

Fig. 1. Graphical dependences $\mathrm{C}=\mathrm{f}(\mathrm{t})$ of soybean oil extraction with dichloromethane

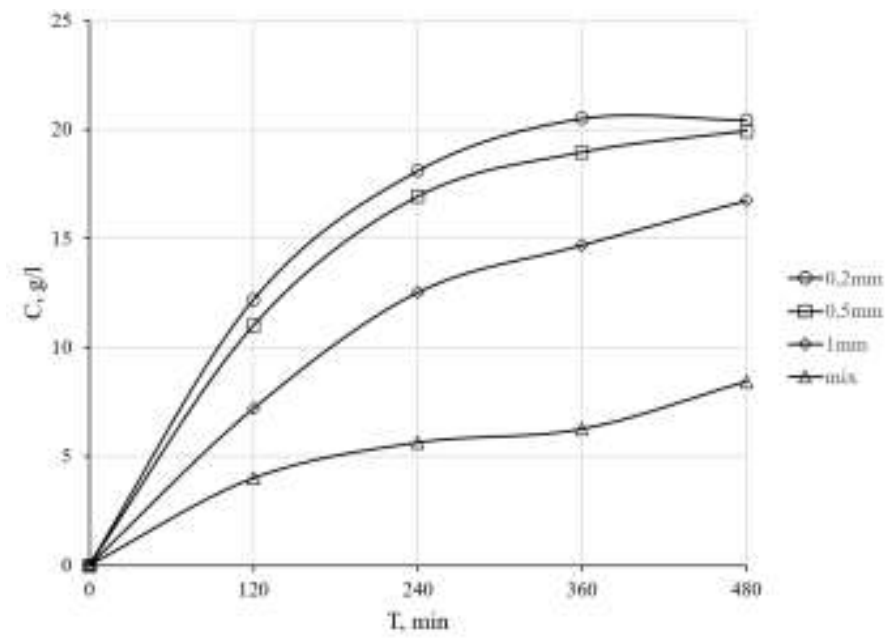

Fig. 2. Graphical dependences $\mathrm{C}=\mathrm{f}(\mathrm{t})$ of soybean oil extraction with ethanol

The results of experimental studies show that for each selected solvent the accumulation of the target product increases over time (Fig. 1,2). Graphical dependences of vegetable oil yield on time $\mathrm{C}=\mathrm{f}(\mathrm{t})$ indicate that the main oil extraction occurs during the first $360 \mathrm{~min}$ of the experiment. Comparing the results for both solvents, it is obvious that the use of dichloromethane and increasing the level of grinding has a positive effect on the oil extraction process.

From Fig. 1 it is obvious that a greater degree of grinding contributes to the efficiency of extraction when using dichloromethane, at the same time as for ethanol such an effect is not observed. Therefore, in the case of dichloromethane, the grinding of the raw material has a greater effect on the final oil yield by increasing the contact area of the phases.

Also, to compare the efficiency of extraction with the investigated solvents, additional studies of two more polar solvents - isopropanol and n-propanol. 


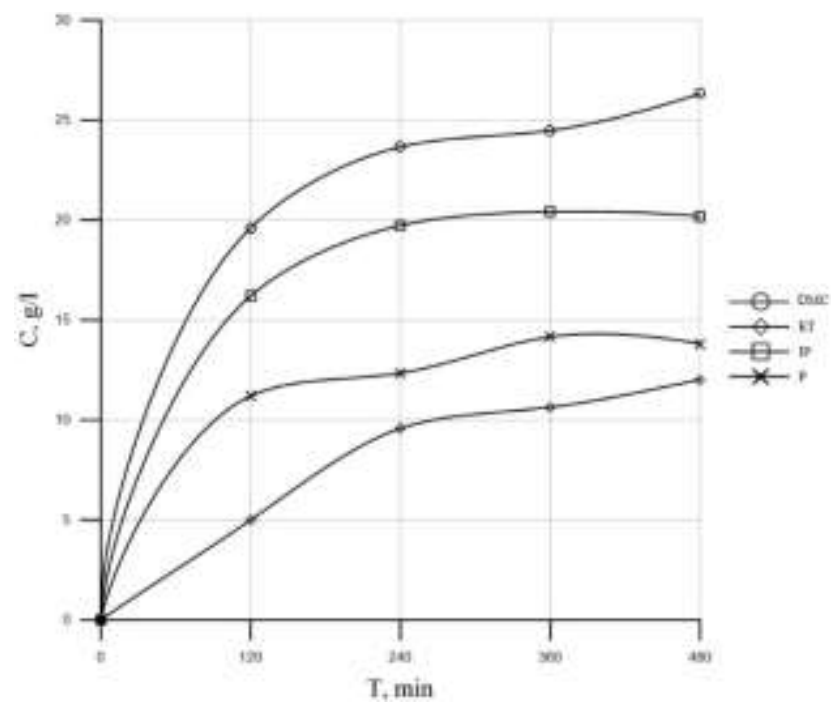

Fig.3. Graphic dependences $\mathrm{C}=\mathrm{f}(\mathrm{t})$ for the rate of accumulation of soybean oil by extraction with polar solvents.

The results of changes in oil concentration in samples over time and the final yield of soybean oils are shown in graphical form in Fig. 3. The increase in the rate of accumulation of the target product increases in a number: ET $<$ P $<$ IP $<$ DCM.

The results of the analyzes to determine the chemical constants and refractive index of soybean oil for different fractions extracted with dichloromethane are given in Table 1.

Table 1

Qualitative analysis results of soybean oil obtained from fractions of different grinding (extractant - dichloromethane)

\begin{tabular}{|c|c|c|c|c|c|}
\hline \multirow{2}{*}{ Parameter } & \multicolumn{4}{|c|}{ Fraction size } & \multirow{2}{\text{Standart}}{$\begin{array}{c}4534: 2006 \\
\text { (Ukraine), unrefined }\end{array}$} \\
\cline { 2 - 5 } & $0,2 \mathrm{~mm}$ & $0,5 \mathrm{~mm}$ & $1 \mathrm{~mm}$ & $\operatorname{mix}$ & $0,922-0,934$ \\
\hline Density, kg/m3 & 0,91 & 0,92 & 0,94 & 0,91 & $\leq 100$ \\
\hline Iodide number & 124,33 & 94,73 & 95,51 & 119,87 & $\leq 4,0$ \\
\hline Acid nubmer & 6,39 & 4,37 & 2,86 & 3,94 & - \\
\hline Ester number & 196,06 & 179,62 & 148,47 & 204,97 & $186-195$ \\
\hline Saponification number & 202,45 & 183,99 & 151,33 & 208,90 & $1,468 \pm 0,07$ \\
\hline Refractive index & 1,4765 & 1,4753 & 1,4787 & 1,4761 & \\
\hline
\end{tabular}

Indicators of IN, AN, EN and saponification number for the obtained soybean oil samples increase with decreasing degree of grinding of raw materials (Table 1). The closest to the standard are the indicators for the sample obtained from the fraction of average diameter $\mathrm{d}=0.5 \mathrm{~mm}$.

Fig.4 presents the data of ultraviolet spectroscopy (UV-Vis) obtained for samples of soybean oil, presented as the dependence of absorption on the wavelength $\alpha=f(\lambda)$. The obtained spectra of oils are characteristic and do not differ from the UV spectra of pure vegetable oils.

The results of spectral IR analysis of the studied oil samples are presented below in the form of graphs of spectral absorption in Fig.5.

The obtained IR spectra showed the presence of alkyl residues of triglycerides (the main components of vegetable oils), as evidenced by peaks with a wave number close to $2900 \mathrm{~cm}^{-1}$. However, there are also slight differences in absorption for the groups $-\mathrm{C}=\mathrm{O}\left(1700 \mathrm{~cm}^{-1}\right)$ and $-\mathrm{C}$ $\mathrm{O}\left(1200 \mathrm{~cm}^{-1}\right)$. This may mean that the test samples contain different amounts of compounds with these functional groups. 


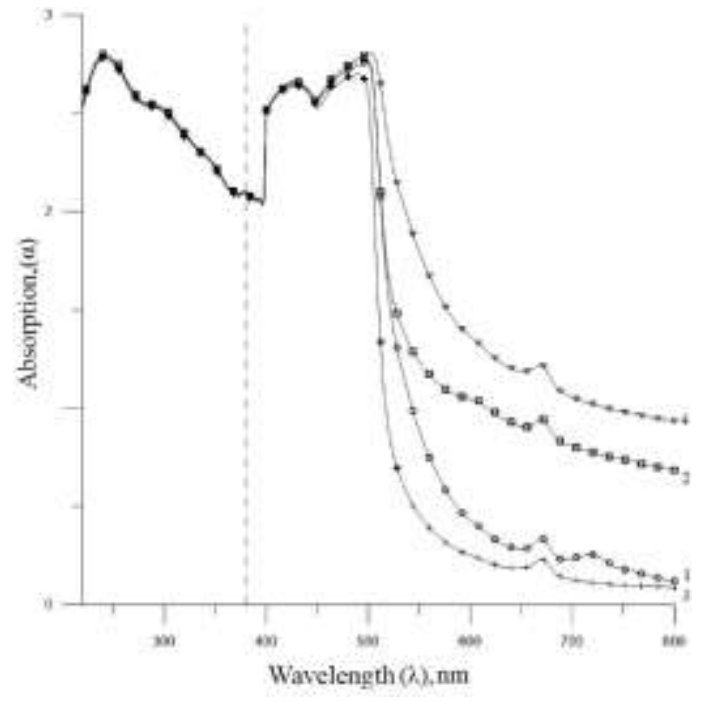

Fig4. Normalized UV-visible absorption spectrum of samples of soybean oil (1 mixture; 2 - $0.5 \mathrm{~mm} ; 3$ - $0.2 \mathrm{~mm} ; 4$ - $1.0 \mathrm{~mm})$.

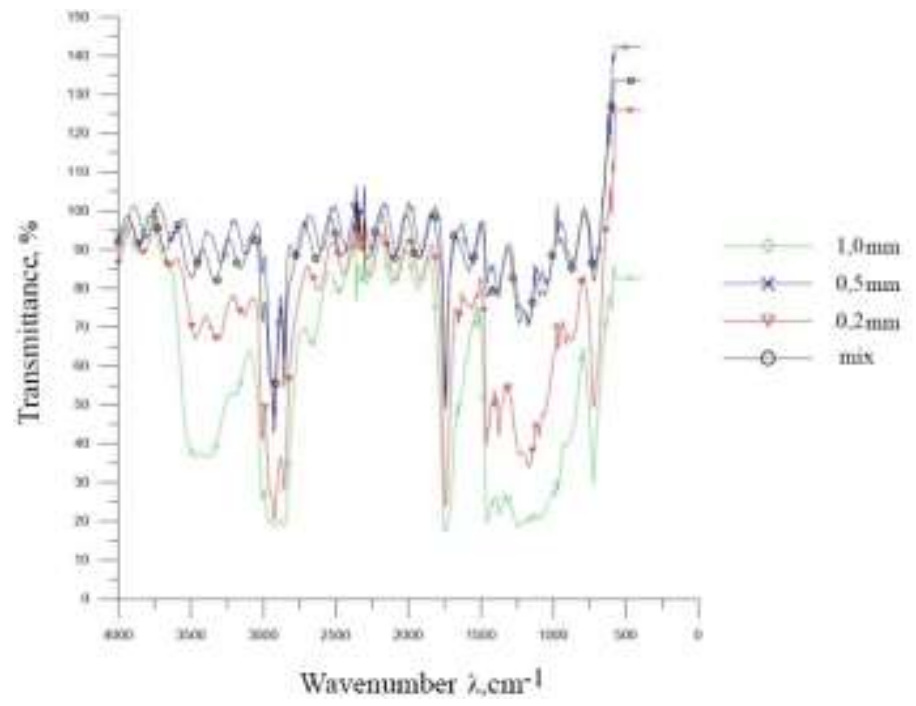

Fig.5. IR spectra of soybean oil sample

\section{Conclusions}

The analysis of the results of research on the process of extraction of oil from different fractions of crushed raw materials indicates that one of the most influential factors in the intensification of extraction is grinding. In the case of dichloromethane, extraction of oil from the crushed mixture is economically feasible, the oil yield reaches the average value between the investigated separated fractions at the level of the average equivalent particle size of $0.5 \mathrm{~mm}$, in industrial conditions it will reduce energy costs. The qualitative analysis slightly deviates from standardized values, so the nature of the causes of these differences should be investigated in more detail.

\section{References}

[1] Kovalchuk, S.Ia. (2010). Rozvytok motyvatsiinykh mekhanizmiv vyrobnytstva biolohichnykh vydiv palyva. Zbirnyk naukovykh prats Vinnytskoho derzhavnoho ahrarnoho universytetu, 42(1), 125-130.

[2] Harish, N., Anil Kumar, K., D. Srinivas \&amp; Sivala Kumar. (2017). Review on Oil Extraction Techniques. International Journal of Agricultural Science and Research (IJASR), 567-576

[3] Syrotiuk, S.V. (2000). Mekhanizatsiia pererobky ta zberihannia produktsii roslynnytstva: Kurs lektsii, 2, Lviv: LDAU, 249.

[4] Semenyshyn, Ye., Atamanyuk, A., Rymar, T. et al. (2020). Mass transfer in the solid-liquid system: mechanism and kinetics of the extraction. Chemistry and Chemical Technology, 14 (1), 121-128.

[5] Ivashchuk, O., Hlukhaniuk, A., Semenyshyn, Ye., Chyzhovych, R., Kuzminchuk, T., Khomyak, S. (2021). Influence of extraction conditions on qualitative composition of vegetable oils. Chemistry \& Chemical Technology, 15(2), 233-238. https://doi.org/10.23939/chcht15.02.233

[6] Ivashchuk,O., Atamanyuk, V., Semenyshyn, Ye., Hlukhaniuk, A., Chyzhovych,R., Kuzminchuk T. (2020). The research of the rapeseed oil extraction for the biodiesel production. Chemical and Process Engineering for Environment and Health. Monography, 49-56. ISBN978-83-7789-629-7.

[7] Ioffe, B.V. (1974). Refraktometricheskie metody`khimii. L.: Khimiya, Leningr., 174. 